Anuario de

Derechos Humanos 2005 


\section{Reunión Regional sobre Transparencia, Rendición de Cuentas y Lucha contra la Corrupción en América}

Documento de Referencia*

Santiago de Chile

3 - 5 de diciembre de 2004

\section{PROPÓSITO DE ESTE DOCUMENTO DE REFERENCIA}

E ste documento recoge los distintos puntos de vista enviados por los participantes de la reunión, en respuesta a la pregunta sobre el campo de Transparencia, Rendición de Cuentas y Lucha contra la Corrupción, su evolución, sus características, sus componentes institucionales y disciplinarios y sus principales sub-campos o líneas de acción.

También recoge las percepciones de los participantes sobre lo que se ha avanzado en este campo, principalmente en América Latina, y sobre las dificultades que se enfrentan, así como sus sugerencias sobre las prioridades para el trabajo futuro, tanto temáticas como organizacionales, y sobre las estrategias para abordarlas.

Se pretende con esta sistematización que todos los participantes cuenten con un panorama general de la visión de los demás participantes acerca del tema que nos convoca. De este modo, podemos aprovechar mejor el tiempo de la reunión para concentrarnos en: (a) trazar un "mapa" general de lo que se está haciendo dentro de este campo internacionalmente y en nuestra región; (b) cotejar experiencias; (c) conversar sobre prioridades para el trabajo futuro y formas de coordinación y cooperación entre distintas organizaciones.

\section{SOBRE EL CAMPO "TRANSPARENCIA, RENDICIÓN DE CUENTAS Y LUCHA CONTRA LA CORRUPCIÓN"}

Aclaración preliminar: Lo que se expone en esta parte del documento no es una visión necesariamente compartida por todos los participantes. Estos hicieron Ilegar, con antelación a la reunión, muchas ideas sobre las características u orígenes de lo que pueda denominarse un campo emergente sobre "Transparencia, Rendición de Cuentas y Lucha Contra la Corrupción". Sin embargo, también se plantearon diversas reservas o calificaciones a esta idea.

En lo que sigue se toman en cuenta todas las opiniones recibidas, complementándolas con datos adicionales, cuando ello ha parecido útil.
* Este Documento de Referencia fue preparado por José Zalaquett para la Reunión Regional sobre Transparencia, Rendición de Cuentas y Lucha contra la Corrupción en América, sobre la base de las opiniones enviadas con antelación por los invitados a la misma.
Este documento está disponible en formato digital en www.anuariocdh.uchile.cl 
Esta sección no tiene un propósito académico ni intenta forzar caracterizaciones o definiciones sobre este campo. Su sentido es proveer una especie de telón de fondo acerca de este campo, como antecedente para las discusiones de la reunión, las que se espera estén más orientadas hacia cómo ampliar y mejorar acciones concretas en pro de la transparencia y rendición de cuentas y en contra de la corrupción en nuestra región.

\section{Dos caras: lucha contra la corrupción y pro transparencia, rendición de cuentas y participación política}

La lucha contra la corrupción y el trabajo pro transparencia, rendición de cuentas y participación política se presentan a menudo como las caras positiva y negativa de la misma medalla.

Sin embargo, una primera salvedad que han formulado algunos participantes es que no toda agenda pro transparencia o accountability puede englobarse dentro de "lucha contra la corrupción". Hay organizaciones y movimientos que se ocupan específicamente de este último enfoque. Por otra parte hay organizaciones que se valen de mecanismos de participación y control, de rendición de cuentas y de libre acceso a información como herramientas para avanzar en su propia agenda, que con frecuencia versa sobre la promoción y defensa de derechos (derechos humanos, derechos ambientales, derechos de usuarios y consumidores, defensa de derechos civiles o acciones de promoción y defensa de derechos vía litigios de interés público). No es fácil por tanto, definir un "campo" propio a partir del uso de los mencionados mecanismos.

Desde esta misma perspectiva, es difícil hablar propiamente de un "campo nuevo" en la medida que esta actividad sería una continuación de una línea de monitoreo y fiscalización de la sociedad civil frente a decisiones tomadas en instancias estatales que afectan intereses y valores generales. (Aunque, por otra parte, no cabe duda que la lucha anti-corrupción y en pro de la transparencia y rendición de cuentas ha adquirido mayor relevancia y contornos propios como tema y como movimiento). Por tanto, este ámbito de transparencia, rendición de cuentas y anticorrupción se puede ver como un producto del desarrollo de procesos previos, tales como: (a) el avance de la idea de que las políticas públicas son, por cierto, materia de Estado y de los partidos políticos (sistema político) pero también de la sociedad en general, por la repercusión que tienen sobre todos; (b) la consolidación y la diversificación del papel de la sociedad civil, como una modalidad de participación particular y su mayor capacidad y legitimidad, lo que ha permitido niveles de monitoreo y de participación en asuntos públicos más complejos y sofisticados; (c) el incremento o la mayor percepción de la corrupción, producto de la falta de transparencia y de mecanismos de rendición de cuentas. 


\section{2. ¿Qué explica el desarrollo de este campo en nuestra región?}

Dejando constancia de la salvedad anterior, la opinión general de los participantes es que efectivamente se puede decir que existe un campo nuevo o emergente de "transparencia, accountability, y lucha contra la corrupción".

\subsection{En cuanto a conceptos o nociones centrales sobre corrupción,} las respuestas recibidas de los participantes consignan las siguientes ideas:

- Por "corrupción" se entiende una práctica o fenómeno que supone el uso o abuso de poderes y funciones públicas para generar indebidamente riqueza o beneficios privados.

- La corrupción puede ser una práctica esporádica o un fenómeno endémico. Este último puede ser focalizado (por ejemplo, en la policía, la judicatura o el servicio de aduanas) o generalizado. La corrupción endémica, sea más focalizada o más general dentro del aparato del Estado, supone un problema estructural, con dimensiones institucionales y también sociales o culturales.

- Salvo ciertas prácticas específicas, la corrupción por lo general envuelve la participación de agentes del Estado y también de actores privados.

- En cuanto al rol de actores privados, es preciso destacar el problema de captura del Estado que se da cuando determinadas elites políticas, económicas y/o sociales, actuando sin necesariamente violar de modo ostensible la ley, ejercen una influencia o control determinante en los poderes del Estado y en el contenido de medidas o políticas públicas que les interesan.

- También hay que destacar las dimensiones internacionales del fenómeno de la corrupción y de la lucha anti-corrupción.

\subsection{En cuanto a conceptos o nociones centrales sobre la "cara}

positiva" de transparencia y rendición de cuentas:

- Estos conceptos se encuentran a la base de la teoría democrática. Se supone que: (a) La soberanía reside en el pueblo, quien delega gran parte de su ejercicio en autoridades elegidas por él; (b) como delegatarias de los ciudadanos, las autoridades cumplen una función al servicio del bien común, de modo impersonal, sujetas a las leyes y a responsabilidades especiales; $(c)$ entre sus responsabilidades se cuentan responder ante sus mandantes, los ciudadanos, dando cuenta de su gestión; (d) los ciudadanos pueden ejercer, como mandantes, una función de participación, supervisión o fiscalización y control de la gestión estatal, no solamente mediante elecciones periódicas, sino en todo tiempo a través del ejercicio de sus derechos de expresión, asociación, manifestación y petición, entre otros; (e) para permitir todo lo 
anterior, la transparencia de la gestión e información pública debe ser la regla general.

- Una debida aplicación de los criterios precedentes, supone una transparencia activa, esto es, la práctica de las autoridades de adelantarse a poner al alcance del escrutinio público la información pública relevante, en oposición a una actitud pasiva de aguardar a que se le solicite formalmente, en uso del derecho de libertad de acceso a información pública.

- Si bien todo lo anterior puede entenderse como parte de la noción de democracia, su realce, en tiempos recientes, responde a diversos factores, entre ellos, la revaloración de la idea de democracia y el desarrollo, en muchos países, de una sociedad civil activa.

- La expresión en castellano "rendición de cuentas" no refleja todavía todas las connotaciones anteriormente expresadas, las cuales sí recoge, en mayor medida, el término accountability (transparencia tanto pasiva como activa, responsabilidad especial del agente público ante sus mandantes, transparencia y fiscalización ciudadana).

\subsection{En cuanto a distintos factores que explican el surgimiento de este campo:}

- El surgimiento de este campo en nuestra región estaría asociado al proceso de democratización y a la disolución gradual de las grandes dicotomías entre izquierda y derecha que tuvo lugar desde los años ochenta, dentro de un cuadro de desmantelamiento del marco de la Guerra Fría. Como parte de estos procesos, la buena gobernanza democrática se transforma en un tema transversal. También se toma mayor conciencia de que la honestidad y transparencia son un presupuesto necesario para otros valores democráticos, como la eficiente gestión pública, la igualdad y la confianza en el sistema político.

- Reiterando la misma idea anterior, desde otra perspectiva, se plantea por algunos participantes que como parte de la lucha por los derechos humanos, en tiempos de dictadura, se fortaleció la sociedad civil y el mundo no gubernamental en muchos países. Con el paso del tiempo, luego del regreso a gobiernos democráticamente elegidos en nuestra región, se suscitó una desilusión, en la mayoría de los países, respecto de la realidad concreta de los sistema políticos y la cultura política imperante, en cuanto subsisten problemas de debilidad institucional y política, corrupción, exclusión social y pobreza. Entonces, la lucha anti-corrupción sería parte de un esfuerzo por legitimar/consolidar las democracias recuperadas. Mirada así, la agenda por la transparencia y contra la corrupción sería uno de los temas de un activismo ético de "segunda generación", luego del período de graves violaciones a los derechos humanos. La lucha anti-corrupción también expresa la continuidad del protagonismo 
público de personas y organizaciones que se movilizaron en el pasado por la defensa de los derechos fundamentales y otras causas que interesan a todos y que ahora tienen "autoridad moral" para formular estas nuevas exigencias de ética política.

- Otra variante de la misma idea destaca que el activismo pro derechos humanos en un clima de recuperación democrática se orienta hacia una mayor realización de los derechos económicos, sociales y culturales y los temas anti-corrupción y transparencia son muy pertinentes en ese tipo de trabajo.

- Desde una perspectiva económica, en los últimos 15 ó 20 años América Latina se ha visto insertada en la economía global de un modo tal que la coloca bajo un escrutinio más intenso de parte de inversionistas y órganos financieros internacionales; bajo este examen, las prácticas de corrupción afectan la libre competencia. Por otra parte, el fracaso de las reformas económicas que se impusieron en la región como parte del "Consenso de Washington" para lograr crecimiento económico, ha dado paso a una "nueva oleada" de proposiciones de reformas institucionales democráticas, como un prerrequisito para reformas económicas exitosas. Desde este ángulo, corrupción pasa a ser sinónimo de obstáculos para una reforma institucional seria.

- Desde una perspectiva internacional, se puede destacar la influencia que ejercen sobre países como los nuestros, los distintos desarrollos que tienen lugar en otros países o en el plano internacional. Este es un fenómeno que ya se conocía a partir de la evolución del movimiento de derechos humanos, en los años setenta y ochenta y, más tarde, con posterioridad a la Guerra Fría, con temas como los de transición a la democracia y la necesidad de alcanzar verdad, justicia y reparaciones frente a los crímenes del pasado reciente. En estas materias, los ejemplos y experiencias de cada país se difunden cada vez más rápidamente. En cuanto al campo que nos ocupa, el hecho que, por ejemplo, se hayan adoptado leyes de libertad de acceso de información prácticamente en toda Europa, además de América del Norte, o la actividad de organizaciones internacionales como Transparencia Internacional, han contribuido a similares desarrollos en nuestra región.

\section{Distintas perspectivas disciplinarias sobre transparencia, accountability y corrupción}

\subsection{Perspectivas normativas: la ética política democrática y el derecho}

- Por ética política democrática se entiende un conjunto de normas morales generalmente aceptadas que han surgido de la teoría y práctica de la democracia y que se refieren a un deber ser (esto es, criterios para determinar qué es justo, correcto o bueno) en materia de: (a) instituciones políticas (incluidos los sistemas legislativos); (b) políticas públicas; (c) conducta y acciones de los agentes públicos. 
- A su vez, el concepto ético de agente público es amplio, incluyendo no sólo a quienes detentan legalmente ese status (autoridades elegidas, funcionarios de exclusiva confianza de éstos y servidores públicos, cualesquiera sea su forma de vínculo laboral con el Estado) sino también todos aquéllos que de facto pueden comprometer la responsabilidad moral y/o legal del Estado. También puede incluir a actores privados, en la medida en que ejerzan funciones que gravitan sobre el bien común, como resultado de una especie de delegación o privatización de funciones públicas (por ejemplo, funciones relativas al funcionamiento del mercado de capitales o de servicios de salud o de previsión social, o bien de suministros de utilidad pública).

- En lo que se refiere a las normas sobre transparencia y probidad pública, tanto la ética política y el derecho, en la mayoría de las sociedades democráticas, buscan proteger similares valores, entre ellos: (a) el patrimonio y los recursos públicos; (b) lo que puede llamarse el orden público económico, esto es, las instituciones, reglas y prácticas que gobiernan el buen funcionamiento del sistema económico, incluyendo los principios de competencia libre y leal, transparencia y reglas del juego parejas para todos; (c) el adecuado funcionamiento de la democracia, incluyendo el respeto a la ley y al estado de derecho, la calidad y eficiencia de la gestión pública, la integridad de las instituciones y las autoridades, y la confianza pública en las mismas; (d) los sistemas de resguardo para cautelar los anteriores valores frente a situaciones que los hacen vulnerables (normas sobre inhabilidades, incompatibilidades, negociaciones incompatibles, etc.).

- Tanto las normas de ética política como las de derecho en la mayoría de los países democráticos, coinciden en gran medida en calificar de ilícitas ciertas conductas o prácticas. Sin embargo, existen conductas o prácticas moralmente reprobables y que son, en cambio, indiferentes para el derecho; y viceversa.

\subsection{Perspectiva normativa específica: la ética política democrática}

- En una visión de la ética política democrática, la probidad pública y la prevención y sanción de la corrupción son temas que atañen a la institucionalidad y las leyes, a las políticas públicas y a la conducta de los agentes públicos. El énfasis suele ponerse en esto último, aunque tomando en cuenta los factores institucionales y de políticas públicas como elementos que inciden en el problema, su prevención o combate. Desde la mirada de la participación ciudadana en temas de ética política, la causa pro transparencia y rendición de cuentas y contra la corrupción puede considerarse como una extensión natural del temario de derechos humanos. Si en una etapa surgió un movimiento ciudadano para combatir los abusos del monopolio estatal de la fuerza, ahora hay también mayor conciencia ciudadana y disposición a oponerse a prácticas que 
suponen el abuso de otras facultades y poderes estatales: aquellos que pueden generar, ilícitamente, beneficios privados.

- En cuanto a conductas específicas de abuso de poderes estatales para beneficio privado, hay prácticas que en muchos países no son ilegales o que se encuentran en una zona gris de legalidad, las cuales, sin embargo merecen un reproche o cuestionamiento desde un punto de vista ético. Por ejemplo:

- La institución de los gastos reservados, que permite a ciertas autoridades disponer de ciertos fondos públicos de modo secreto y discrecional y sin que haya mecanismos de control.

- La llamada "puerta giratoria", práctica que consiste en que un regulador estatal deja su cargo público para inmediatamente ser contratado por una empresa privada de aquellas que regulaba.

- Ciertas formas de clientelismo o nepotismo (la ley suele prohibir algunas de estas conductas, pero sin incluir muchas otras que son excesivas en relación a la necesidad política de contar con funcionarios de confianza).

- Ciertas formas de financiamiento político y electoral que tienden a generar una influencia indebida de parte de los donantes sobre los agentes públicos electos.

- Ciertos conflictos de intereses o negociaciones incompatibles (la ley suele prohibir ciertas de estas conductas, pero sin incluir otras que son parecidamente reprochables).

- También suele ser materia de preocupación ética antes que una ilegalidad manifiesta, la situación más general o estructural que más arriba hemos llamado "captura del Estado" por parte de determinados grupos de influencia.

\subsection{Perspectiva normativa específica: el derecho}

El derecho internacional y las legislaciones nacionales de la mayoría de los países democráticos, abordan el tema de la probidad pública desde una perspectiva doble: preventiva/promocional y sancionatoria. Muchas de las principales medidas preventivas/promocionales se detallan más abajo, a propósito del enfoque disciplinario desde la teoría de la gestión pública.

Desde una perspectiva jurídica, son ilícitas las conductas tipificadas como tales por la ley. En el campo de la probidad pública, las siguientes son las conductas más frecuentemente tipificadas como ilícitas tanto en leyes nacionales como en las convenciones internacionales:

- El hurto, la apropiación indebida o el uso indebido para fines privados, por parte de agentes públicos de bienes o caudales públicos (no necesariamente supone la co-participación de agentes privados). 
- El fraude al fisco (no necesariamente supone la co-participación de agentes privados).

- El soborno, entendido como la dádiva o promesa en favor de agentes públicos o de personas vinculadas a ellos, de bienes o servicios, a cambio de que el agente público favorezca al sobornante (cuando esta relación se da entre agentes privados extranjeros y agentes del Estado, se habla de soborno transnacional).

- La extorsión, que supone la misma relación anterior, pero a iniciativa del agente público.

- Las negociaciones incompatibles (no necesariamente suponen coparticipación de agentes privados).

- El tráfico de influencias (no necesariamente supone co-participación de agentes privados).

- El uso abusivo de información privilegiada (no necesariamente supone co-participación de agentes privados).

- Conductas (algunas de las cuales pueden calzar con alguna de las formas ya enumeradas) que violan normas de probidad propias de ámbitos específicos tales como la administración de justicia, la función policial, las licitaciones (y otras formas de adquisición) públicas, las elecciones populares o el financiamiento de partidos políticos.

- El enriquecimiento ilícito, entendido como el incremento del patrimonio de un funcionario público con significativo exceso respecto de sus ingresos legítimos durante el ejercicio de sus funciones y que no pueda ser razonablemente justificado por él. (Esta figura delictiva ha sido tipificada en algunos de nuestros países, pero ha despertado reserva en otros a partir de consideraciones teóricas de derecho penal sobre el peso de la prueba o sobre responsabilidad objetiva).

Las normas jurídicas internacionales establecen, además, obligaciones o facultades estatales como las siguientes:

- Cooperación internacional en la prevención, incluyendo labores de inteligencia e intercambio de información, la prosecución y castigo de conductas corruptas.

- Específicamente, normas que permiten o facilitan la extradición respecto de estos delitos.

- Obligación de proteger a los denunciantes de estas prácticas o conductas, así como otras medidas preventivas que se detallan a continuación a propósito de la perspectiva de la gestión pública.

- Posibilidad de que los Estados establezcan ciertas formas de jurisdicción extraterritorial sobre estos delitos. 


\subsection{La perspectiva de la gestión pública}

Desde esta perspectiva interesan, sobre todo, los principios y prácticas de la gestión del Estado que promueven la probidad y eficiencia en el desempeño del servicio público, tienden a prevenir y controlar la posibilidad de corrupción o, cuando ésta tiene lugar, a enfrentarla y superarla. Algunos de los principales principios y prácticas (muchos de los cuales han sido incorporados en las convenciones anticorrupción) se pueden agrupar de la siguiente manera:

- Fomentar una cultura de probidad y eficiencia en el servicio público, a través de medidas tales como: (a) La solemne consagración del establecimiento de los principios de probidad y transparencia en la Constitución y las leyes; (b) la elaboración de normas o códigos de conducta profesional; $(c)$ el correspondiente entrenamiento y capacitación de los funcionarios.

- Impulsar apropiadas políticas de recursos humanos para la gestión pública, incluyendo sistemas equitativos y transparentes de contratación, remuneración, evaluación y promoción, lo que se estima pueden, además de otros efectos beneficiosos, constituir un incentivo en favor de la probidad.

- Fomentar el libre acceso a la información pública y la transparencia activa.

- Sistemas de declaración jurada sobre patrimonio, ingresos, activos, pasivos e intereses de determinados funcionarios públicos.

- Mecanismos modernos y eficientes de control de legalidad, de cuentas y/o de mérito.

- Sistemas transparentes, equitativos y eficientes de adquisición por parte del Estado de bienes y servicios y de recaudación tributaria.

- Sistemas de protección de funcionarios públicos que denuncien la corrupción.

\subsection{Otras perspectivas disciplinarias}

El fenómeno de la corrupción también puede ser analizado desde diversas otras perspectivas disciplinarias. Por ejemplo:

- Para la economía interesa, entre otros aspectos: (a) estudiar los efectos de la corrupción sobre el costo de la inversión y sobre el crecimiento o, desde una perspectiva económica más integral, sus efectos sobre el desarrollo humano; (b) identificar las reglas del juego económicas en materia de transparencia, equidad y prontitud en la toma de decisiones que aseguren un leveling field, o "terreno parejo" para los actores económicos, y prevengan la corrupción; (c) estudiar la pertinencia y eficacia de sistemas regulatorios, incluyendo la regulación para proteger a accionistas minoritarios; $(d)$ analizar factores (tributarios, cambiarios, de tipos de tasa de interés o de sistemas de adquisición pública) que incentivan o desincentivan la corrupción. 
- Para las ciencias sociales, incluyendo la ciencia política, la sociología y psicología social, interesa, entre otros aspectos, (a) estudiar los factores estructurales, de carácter político, social o cultural, que inciden en el nivel de expectativas y de confianza en las instituciones públicas (o en lo que se ha dado en llamar la gestación de una sociedad de confianza); (b) los grupos, alianzas y redes sociales de influencia, apoyo o protección recíproca, así como los mecanismos que facilitan su reproducción y perpetuación; (c) el impacto de la corrupción en la calidad del sistema político, así como su costo social y su incidencia cultural.

- Se puede hablar también de un saber que emana de la experiencia y la acción de la sociedad civil en esta materia. Así sucedió con el movimiento de derechos humanos, que fue creando, a través de la práctica, un extraordinario acervo de información y documentación, así como un nuevo tipo de conocimiento profesional sobre situaciones de hecho, así como sobre acciones y medidas conducentes a enfrentarlas. Tal conocimiento tiene una dimensión inter-disciplinaria, pero está conformado también, y quizás en medida más importante, por un saber enraizado en la práctica. Este campo de "saber" y de acción ha sido objeto, a posteriori, de estudios académicos desde diversas disciplinas. Lo propio podría estar comenzando a desarrollarse en el todavía emergente campo de trabajo práctico en pro de la transparencia y rendición de cuentas y contra la corrupción.

\section{Componentes y actores del campo de transparencia, rendición de cuentas y lucha contra la corrupción}

En esta sección se procura hacer un bosquejo general de los principales componentes y tipos de actores dentro del campo emergente que nos ocupa. Por cierto, estos componentes y actores son conocidos por los participantes de la reunión. Se espera que el esquema que sigue pueda tener utilidad como referencia o recordatorio para las discusiones que tengan lugar en el curso de la reunión.

\subsection{En el plano internacional y regional}

- Las distintas organizaciones intergubernamentales, tanto Naciones Unidas (ONU) como la Organización de Estados Americanos (OEA), el Consejo de Europa (CE), la Organización de Unidad Africana (OUA) y la Organización para la Cooperación y el Desarrollo Económico (OCDE), así como instancias regionales para el Asia Pacífico han desarrollado convenciones (la Convención Africana se encuentra todavía en proceso de redacción) así como programas o iniciativas especiales anti-corrupción.

- Organizaciones multilaterales financieras, monetarias, de fomento o de comercio, como el Banco Mundial (BM), el Fondo Monetario Internacional (FMI), la Organización Mundial de Comercio (OMC) o el Banco Interamericano de Desarrollo (BID), también han 
formulado políticas, establecido programas especiales o impulsado estudios sobre la materia.

- Hay también organizaciones internacionales de carácter no gubernamental especializadas en el tema, como es bien sabido, y dos de ellas, Transparencia Internacional y TIRI, están presentes en esta reunión. Organizaciones como Probidad, también presente en esta reunión, tienen un enfoque regional (Centro América). Organizaciones no gubernamentales regionales de América Latina cuyo mandato principal es de derechos humanos, como el Instituto Interamericano de Derechos Humanos (IIDH) o la Comisión Andina de Juristas (CAJ), tienen departamentos o programas que inciden sobre temas de probidad pública. En este sentido, también es pertinente mencionar la práctica de misiones de observación electoral para verificar el cumplimiento con los estándares internacionales, que se ha difundido internacionalmente, incluyendo en nuestra región, desde los años ochenta.

- Fundaciones y agencias donantes privadas internacionales también han establecido una línea de grants para financiar proyectos en este campo o bien ejecutan sus propios programas.

\subsection{En el nivel nacional}

No en todos los países de nuestra región se encuentran todos los componentes o actores que se bosquejan a continuación y, en todo caso, la presencia e importancia de ellos varía de país en país:

- Normas legales relevantes, así como incorporación a la legislación nacional de convenciones (de ONU o de la OEA) anti-corrupción. Estas normas por lo general establecen principios generales de promoción, prevención y control de la probidad pública o tipifican conductas ilícitas. Se han hecho frecuentes las leyes de acceso a información pública y/o de obligación de transparencia activa por parte de entes públicos. En cambio, la legislación que permite acciones de interés público en esta materia es todavía muy incipiente.

- Políticas públicas, sean programas o planes generales de probidad o políticas específicas, como por ejemplo, las que se refieren a adquisiciones públicas.

- Organismos estatales especiales encargados de ejecutar tales planes o políticas estatales o de asesorar a las autoridades, tales como comisiones de probidad pública o departamentos o unidades especiales en determinados ministerios.

- Organismos estatales especiales de control, supervisión, sanción administrativa o denuncia, tal como contralorías, auditorías internas en distintas entidades públicas o departamentos especializados en las defensorías del pueblo.

- Organismos de administración de justicia, allí donde se han creado fiscalías especiales o bien donde determinados fiscales o jueces 
han asumido un papel especialmente activo para investigar conductas de corrupción.

- Organizaciones de la sociedad civil, incluyendo filiales o capítulos de Transparencia Internacional. El mandato o temario de estas organizaciones varía, pero, por lo general, tienden a la especialización, concentrándose en materias tales como libertad de acceso a información (las más numerosas), promover la transparencia y supervisión ciudadana de la elaboración y ejecución de presupuestos públicos o trabajar por reformas electorales y transparencia en el financiamiento político.

- Como ya se ha dicho, hay organizaciones que se ocupan en general de abrir espacios de participación y control ciudadano del Estado, (no específicamente de combate a la corrupción) y para ello se valen de mecanismos como audiencias públicas, acceso a la información, abogar por la elaboración participativa de normas legales o garantizar su difusión y utilización. Hay otras organizaciones que también hacen uso de tales mecanismos para avanzar una agenda de derechos civiles, de protección del medio ambiente o de derechos de usuarios y consumidores. En un sentido amplio, si se quiere, puede considerárselas también como partícipes de un campo de transparencia y rendición de cuentas.

- Incipientes programas de investigación y enseñanza en think tanks o en universidades.

\subsection{El rol de la prensa investigativa y la opinión pública}

No puede subestimarse la importancia de la prensa investigativa y de la opinión pública en la creación de una conciencia pública sobre cuestiones de transparencia y corrupción y en la movilización en contra de estas prácticas, tanto a nivel internacional, como, principalmente, en los países afectados. La presión y las protestas de opinión pública han conducido, en distintos países de nuestra región, a renuncias a su cargo de parte de algunos gobernantes, a severos cuestionamientos de otros, así como también han contribuido a que se someta a juicio a agentes públicos, se lleven a cabo reformas políticas y electorales, y se adopte legislación especial o políticas públicas sobre transparencia y sobre castigo a la corrupción.

\subsection{El rol de los actores económicos privados}

El mundo empresarial privado es visto, por lo general, como parte del problema y a la vez como parte de la solución. Por un lado, puede actuar como co-partícipe de actos de corrupción como el soborno, el tráfico de influencias, las negociaciones incompatibles o el uso abusivo de información privilegiada (en este último aspecto, tanto el aprovechamiento de dicha información para mejorar su posición en el mercado como el uso abusivo de dicha información dentro de la empresa por parte de un grupo gerencial o controlador, en desmedro 
de los accionistas pequeños). Por otro lado, a menudo tiene un interés activo en promover reglas de transparencia y equidad que permitan reglas del juego parejas para todos, así como sistemas eficientes y probos de adjudicación de conflictos, con miras a obtener mayor previsibilidad en los negocios y disminuir los costos de inversiones, así como las distorsiones de la economía. Estos temas están también vinculados con la tendencia emergente a enfatizar la responsabilidad social de las empresas.

\section{Evaluación crítica de este campo}

Entre las opiniones enviadas por los participantes que, en su gran mayoría, consideran que sí existe un campo emergente o en formación en estas materias, se formulan las siguientes observaciones sobre dicho campo:

- Todavía está confinado en buena medida a las elites políticas o de la sociedad civil. Por ejemplo, en materia de libertad de acceso a la información, no se ha configurado en nuestra región una preocupación y movilización ciudadana más masiva, como en cambio ha sucedido en países de Europa central y oriental.

- También se echa de menos una articulación o cohesión a partir de conceptos o lenguajes comunes, aunque ello se encuentra en desarrollo, especialmente sobre la base de recientes convenciones internacionales contra la corrupción.

- En este campo se hace necesaria una mayor profesionalización, en la medida en que existen materias técnicas (como por ejemplo, las relativas a control de los presupuestos) que deben abordarse con suficiente rigor para tener un impacto.

- Hay insuficiente articulación o comunicación entre organizaciones de la sociedad civil que incluso trabajan en el mismo país.

\section{SOBRE LA AGENDA PRESENTE Y FUTURA EN ESTE CAMPO}

La mayoría de las opiniones recibidas se refieren a la agenda internacional, regional o nacional en este campo desde el ángulo de la práctica de las organizaciones no gubernamentales y las agencias donantes. Sin perjuicio de ello, durante la reunión conoceremos el punto de vista de varias organizaciones intergubernamentales y podríamos discutir cómo éstos se vinculan con la agenda del mundo no gubernamental.

\section{Objetivos temáticos que estarían alcanzados en grado razonable como para pensar en enfatizar nuevas etapas y prioridades}

Además de señalar los logros que consisten en el desarrollo mismo de organizaciones no gubernamentales y otros desarrollos institucionales y legales dentro de este campo, varios participantes coincidieron en las siguientes apreciaciones sobre avances temáticos. 
En el plano internacional se ha progresado en instalar este tema en la opinión pública, en términos generales, como un asunto tanto de ética política como de buen funcionamiento del Estado, la economía y la sociedad; un asunto que, más aún, involucra a la sociedad civil, a instituciones estatales, a organismos multilaterales políticos y financieros, a actores económicos privados y a la academia. El desarrollo de índices de percepción de corrupción ha contribuido a la cobertura de prensa y al interés de la opinión pública sobre esta materia. Por cierto, queda mucho por hacer en cuanto a crear mayor conciencia, pero la fase inicial de instalar el tema en términos generales en la opinión pública habría alcanzado un satisfactorio grado de cumplimiento que permite apuntar a nuevas etapas y prioridades.

Lo mismo puede decirse de la normativa legal internacional. Las convenciones internacionales anti-corrupción (de ONU, OEA y OCDE), así como otros estándares, constituyen una base suficiente. Interesa ahora, por tanto, tal como se detalla más adelante, concentrarse en el seguimiento del cumplimiento de las obligaciones que estas convenciones imponen y en su implementación práctica.

En el plano nacional, la situación, en lo que toca a avances en temas determinados, varía de país en país. En muchos de los de nuestra región, los ecos de las tendencias internacionales, así como algunas investigaciones periodísticas y judiciales locales sobre escándalos de corrupción o sobre falta de transparencia, han contribuido a generar una conciencia pública sobre el tema. En cuanto al marco jurídico para consagrar los principios de probidad pública y castigar actos de corrupción, existen, por lo general, bastantes normas legales, aunque haya algunas conductas que más arriba en este documento se señalan como moralmente reprobables (ver sección I. 3.2.) que no están tipificadas como ilegales en la mayoría de los países americanos. También subsiste el problema de la insuficiente incorporación al derecho interno de las obligaciones contraídas por los Estados al ratificar las convenciones anti-corrupción.

En lo que toca a avances legales en materia de transparencia, existen también, en muchos de nuestros países, leyes de libre acceso a información pública (aunque en varios casos son insuficientes) o incluso de transparencia activa. En lo que se refiere a reforma de sistemas y prácticas electorales se han hecho diversos avances concretos, muchos impulsados por organizaciones de la sociedad civil; con todo, en cuanto al financiamiento de la política, aunque hay ciertos avances, queda mucho más por hacer. Igualmente, los programas de control ciudadano sobre elaboración y/o ejecución presupuestaria, constituyen una línea de trabajo más nueva e incipiente. Sobre los tres temas anteriores, tendremos presentaciones especiales en el curso de la reunión. 


\section{Puntos para la agenda futura}

En esta parte exponemos las opiniones y sugerencias que se hicieron llegar por los participantes, ordenándolas por temas.

\subsection{Enfoque general de la acción a desarrollar en este campo}

Para algunos, el trabajo pro transparencia, rendición de cuentas y anti-corrupción debe sustentarse en una comprensión conceptual no tanto legalista o moralista, sino socio-política del tema "con una visión sistémica y estructural, y un campo de acción concertada, integral, que incluya al Estado, sociedad civil (comprendiendo dentro de ésta al sector privado empresarial) y la opinión pública.

Sin negar la necesidad de coordinación e intercambios, otros enfatizan que las "organizaciones de la sociedad civil deben enfocarse a un objetivo de trabajo lo más especializado posible". (Agregan que para definir formas de colaboración entre grupos y organizaciones sería preciso: (a) identificar las metas que se busca alcanzar en cada área de este campo; (b) tener en claro las fortalezas y debilidades de cada organización para cumplir objetivos precisos; (c) procurar organizar task forces o equipos de trabajo aprovechando las distintas especialidades).

También se ha destacado que no correspondería pensar en una sola agenda regional, aunque haya, desde luego, ciertos temas de interés que van más allá de tal o cual país.

Tampoco correspondería pensar en una "solución" al problema de la corrupción, sino entender más bien que un objetivo realista consistiría en disminuirla en la mayor medida posible y en desarrollar una capacidad de reacción frente a ella.

Otros participantes enfatizaron que el tono general de la acción en este campo debería resaltar los fines positivos que se buscan, como transparencia, accountability, o una democracia eficiente y participativa, antes que insistir en "anti" corrupción.

\subsection{Planes y estrategias nacionales}

Algunos participantes destacan la necesidad de promover a nivel nacional la elaboración de Planes o Estrategias Nacionales sobre transparencia, rendición de cuentas y anti-corrupción, a la manera como en años recientes la oficina del Alto Comisionado de Naciones Unidas para los Derechos Humanos ha promovido la elaboración de Planes Nacionales de Derechos Humanos en distintos países. En el campo de probidad pública, tales planes o estrategias deberían tomar en cuenta el concepto de sistemas de integridad que se ha desarrollado en este ámbito. Tales planes deberían contemplar la creación de una institucionalidad adecuada dentro del aparato del Estado sobre estos temas. 
2.3. Seguimiento de la implementación de las convenciones internacionales

También se enfatiza la necesidad no ya de buscar nuevas normas internacionales, sino de hacer seguimiento del cumplimiento de las obligaciones que imponen las normas existentes para los países que han ratificado las convenciones respectivas. Sobre este punto, escucharemos una presentación en el curso de la reunión.

\subsection{Estudio y documentación del problema de la corrupción}

Se destaca a este respecto la necesidad de:

- Desarrollar estudios sobre el problema desde una perspectiva cuantitativa y cualitativa, más allá de (útiles) estimaciones o índices generales.

- Desarrollar estudios de caso de acuerdo a los estándares generalmente aceptados para estos estudios, con el objeto de facilitar el intercambio de experiencias, la enseñanza y el desarrollo de una disciplina relativa a probidad pública y anti-corrupción.

- Compilar y difundir en mayor medida ejemplos de "buenas prácticas".

- Crear o fortalecer foros, reuniones y programas de intercambio efectivo de experiencias.

- "Mapear" el estado de este campo, esto es, desarrollar tanto inventarios y directorios de organizaciones, redes y programas, así como análisis generales de avances sustantivos.

\subsection{Libertad de acceso a información}

En esta área de trabajo se señalan los siguientes puntos de agenda:

- Promover legislación donde no la haya, o mejoras legislativas, donde la ley es insuficiente.

- Capacitar a funcionarios públicos y también a organizaciones sociales y usuarios, en este último caso para saber usar el sistema y para mejor emplear la información obtenida.

- Estimular el periodismo investigativo.

- Promover litigios para cumplimiento efectivo de las leyes y facilitar redes jurídicas e intercambio de experiencias a este respecto.

- Lograr la institucionalización de una política de educación y capacitación estatal que tenga como uno de sus ejes el respeto al acceso a la información pública como un derecho fundamental. 


\subsection{Control ciudadano sobre la elaboración y ejecución presupuestaria}

Se destaca en este punto tanto la necesidad de promover políticas de transparencia activa, como ya se ha mencionado, así como la necesidad de que organizaciones de la sociedad civil aumenten su nivel de profesionalismo en esta área.

\subsection{Transparencia}

Además de los aspectos ya tratados de libertad de acceso a información, de transparencia activa y del periodismo investigativo, que se relacionan centralmente con la transparencia de la gestión pública, se hace ver la necesidad de exigir y promover procesos abiertos (y, cuando proceda, en consulta con organizaciones de la sociedad civil) en materias específicas tales como el nombramiento de jueces o de candidatos propuestos por los países para cargos internacionales de relevancia en cuestiones de ética política, como ser candidatos a la Comisión Interamericana o a la Corte Interamericana de Derechos Humanos, o a los Comités o relatorías sobre esta materia u otras materias afines dentro del sistema de la ONU.

\subsection{Transparencia de la actividad política}

Como parte del objetivo de establecer transparencia en el financiamiento político y electoral, se mencionó la necesidad de extender tal transparencia al interior de los partidos políticos, velando por el cumplimiento de sus normas de democracia interna, de elecciones intra-partidarias limpias y libres, y por el correcto manejo de las finanzas partidarias.

\subsection{Herramientas}

Entre las herramientas existentes para exigir rendición de cuentas y transparencia, así como para avanzar en otras materias de interés ciudadano general o sectorial, se han mencionado anteriormente el uso de mecanismos de acceso a información, audiencias públicas, participación de la sociedad civil en la elaboración de normas, presupuesto participativo, mecanismos de consulta a sectores afectados o litigios por causas de interés público, colectivo o difuso. A este respecto, se debería promover: (a) la difusión de estas experiencias y su impulso a nivel regional; (b) su evaluación en los países que las han implementado a nivel nacional o local; (c) el perfeccionamiento de algunos de estos instrumentos o la creación de otros nuevos, como por ejemplo, lograr que la ley permita un uso más amplio (y fallos judiciales de alcance más extendido) de litigios por causa de interés público, colectivo o difuso. 
2.10. Coordinación y redes entre distintas organizaciones dentro de este campo y con campos afines

Un participante declara conocer cinco redes en este campo: Transparencia Internacional, Red Interamericana para la Democracia, Acuerdo de Lima, Socios Avina y el IBP (International Budget Project). A ello puede agregarse la Red de Educación sobre Integridad Pública (PIEN), coordinada por TIRI, de la que se habla más adelante, el Justice Initiative patrocinado por OSI y redes de organizaciones como Probidad. (Esta reunión será, esperamos, ocasión propicia para saber más de éstas y otras redes).

En todo caso, muchos participantes establecieron la necesidad de crear redes y otros vínculos de coordinación y comunicación entre organizaciones de la sociedad civil que trabajan en este campo. También destacaron la necesidad de establecer tales vínculos entre las organizaciones que específicamente se ocupan de cuestiones de transparencia/probidad con otras organizaciones de la sociedad civil que tocan algunos de esos temas en algunos de sus programas o se valen en ellos de herramientas tales como como libertad de acceso a información.

También se menciona la necesidad de vincularse con el sector empresarial, en particular respecto de materias tales como el desarrollo y difusión de la noción de responsabilidad social de las empresas.

La búsqueda de una mayor coordinación entre organizaciones debería tener como objetivo la realización de campañas unificadas de presión social para forzar a los gobiernos a implementar los estándares generalmente aceptados en esta materia (las organizaciones financieras multilaterales pueden contribuir a dar fuerza a esas campañas, en la medida en que sus políticas respecto de los gobiernos apunten en la misma dirección; sin embargo, sería un error que tales organizaciones multilaterales trataran establecer las agendas nacionales).

\subsection{Desarrollo de programas de investigación, educación superior y capacitación profesional}

Distintos participantes han puesto énfasis en la necesidad de profesionalizar este campo y capacitar debidamente a quienes trabajan en él, tanto funcionarios públicos como activistas de la sociedad civil o académicos. Ello supone el desarrollo de currículums académicos y materiales de estudios, incluyendo estudios de casos, todo lo cual, a su vez, requiere de cátedras, líneas de investigación académica, así como programas de publicación, traducción y becas.

A este respecto, en el curso de esta reunión tendremos una exposición sobre la iniciativa Red sobre Educación en Integridad Pública (PIEN), que coordina TIRI.

Varios participantes destacan que la capacitación debiera estar dirigida tanto a los profesionales de organizaciones de la sociedad civil, como a funcionarios públicos, incluyendo legisladores y jueces, y a periodistas y comunicadores sociales. 


\section{Prioridades}

Esperamos intercambiar opiniones sobre prioridades en el curso de la reunión. En esta última sección consignamos algunas de las opiniones recibidas:

- ¡Implementación, implementación, implementación! es el "grito de batalla" de una participante, lo cual tuvo un eco en distintas opiniones recibidas. Es una posición que enfatiza que el tiempo de creación de conciencia y de normas debe dar paso ahora, como prioridad, a programas que aseguren el efectivo cumplimiento de las obligaciones que imponen las normas internacionales o bien el uso efectivo de tales normas (si ya están incorporadas en el sistema jurídico nacional) y de las leyes o instituciones nacionales, así como la extensión y difusión de tal uso.

- Por su parte, Transparencia Internacional establece las siguientes prioridades para nuestra región: (a) impulsar Convenciones Internacionales Contra la Corrupción y su implementación; (b) impulsar agendas hemisféricas anti-corrupción; $(c)$ medir la corrupción y los avances; (d) mejorar normativa anti-corrupción en el sector privado.

- Otras prioridades que se señalaron incluyen: (a) reducir la corrupción en la política y en particular en el financiamiento político; (b) reducir la corrupción en las contrataciones públicas; $(c)$ asegurar el acceso a la información; (d) promover la efectiva aplicación, por parte de la justicia, de las normas anti-corrupción. 
